\title{
A New Portfolio Selection Method Based on Interval Data
}

\author{
Madalina Ecaterina Andreica ${ }^{1}$, Ion Dobre ${ }^{2}$, Mugurel Ionut Andreica ${ }^{3}$, Cornel Resteanu ${ }^{4}$ \\ ${ }^{1}$ Bucharest Academy of Economic Studies, 010552, Romania, madalina.andreica@gmail.com \\ 2 Bucharest Academy of Economic Studies, 010552, Romania, dobrerio@ase.ro \\ ${ }^{3}$ Politehnica University of Bucharest, 060032, Romania, mugurel.andreica@cs.pub.ro \\ ${ }^{4}$ National Institute for R\&D in Informatics, Bucharest, 011455, Romania, resteanu@ici.ro
}

\begin{abstract}
The aim of this paper is to extend a portfolio selection method based on MADM techniques for the case of interval data. In order to highlight the procedure of the proposed algorithm an example of product portfolio selection for a leasing company has been analyzed. Several numerical simulations have been performed in order to illustrate our interval data method.
\end{abstract}

Keywords: Multi-Attribute Decision Making, Imprecise Data, Shannon's Entropy, Portfolio Selection, Leasing

\section{Introduction}

The process of decision making is both a permanent necessity and a challenge in many fields, like risk management, banking, operational research and many others. The importance of the decision making process has been confirmed by the large number of publications which develop efficient decision making techniques. These techniques can be classified into several broad categories, such as those handling certain and complete information, those using uncertain data and objectives, and those based on risk assessment $[3,11]$. Some of the best known decision making optimization methods are multi-attribute and multi-objective decision making $[2,7,10]$, fuzzy decision rules [8] and dynamic programming.

Multi-Attribute Decision Making (MADM) refers to making preference decisions over the available alternatives that are characterized by multiple, generally conflicting attributes. In traditional MADM problems, most of the input variables are assumed to be crisp data. However, in most cases it is quite difficult to determine precisely the exact value of the attributes under incomplete information and uncertainty and as a result of this, their values are considered as intervals. Therefore, the aim of this paper is to extend a portfolio selection method based on MADM methods, for the case of interval data. Finally, an example of product portfolio selection for a leasing company is shown in order to highlight the procedure of the proposed algorithm.

The paper is structured as follows. Section 2 presents the portfolio selection method for interval data, for which a numerical example is then given in Section 3, followed by some numerical simulations in Section 4, while Section 5 concludes.

\section{Portfolio Selection Method for Interval Data}

In this section we present an extension of a portfolio selection method [4] for the case of interval data. The portfolio selection problem consists in how to allocate the capital to a number of goods in order to bring a most profitable return for investors. The algorithm consists in combining both a TOPSIS and an ELECTRE III method for interval data in order to select the best portfolio. The reason for choosing these 2 particular methods consists in the following facts. On the one hand, the TOPSIS method is an effective method to determine the ranking of decision alternatives, but cannot, however, distinguish the difference degree between two decision alternatives easily. On the other hand, although the ELECTRE III method can easily compare the degree of difference among all alternatives, it cannot always provide total ordering. That is why, when combining the 2 methods, a final portfolio with better characteristics is obtained. 
For that we consider a general MADM problem that can be summarized in the form of a matrix, in which there are $m$ rows, representing different alternatives and $n$ columns, representing the criteria specifying the properties of the alternatives. In the classical approach the assessment of alternative $A_{i}$ with respect to criterion $C_{j}$ was represented by a real number $x_{i j}$. The components of the vector of weights $w=\left(w_{1}, w_{2}, \ldots, w_{n}\right)$ are real numbers. In our interval data approach, instead of the numbers $\mathrm{x}_{\mathrm{ij}}$ we use the intervals $\left[\mathrm{x}_{i j}^{L}, \mathrm{x}_{i j}^{U}\right]$, the vector of weights is replaced by a vector whose components are intervals $w=\left\{\left[w_{1}^{L}, w_{1}^{U}\right],\left[w_{2}^{L}, w_{2}^{U}\right], \ldots,\left[w_{n}^{L}, w_{n}^{U}\right]\right\}$. The decision matrix in our approach is as follows:

$$
\begin{array}{ccccc} 
& C_{1} & C_{2} & \cdots & C_{n} \\
A_{1} & {\left[x_{11}^{L}, x_{11}^{U}\right]} & {\left[x_{12}^{L}, x_{12}^{U}\right]} & \cdots & {\left[x_{1 n}^{L}, x_{1 n}^{U}\right]} \\
A_{2} & {\left[x_{21}^{L}, x_{21}^{U}\right]} & {\left[x_{22}^{L}, x_{22}^{U}\right]} & \cdots & {\left[x_{2 n}^{L}, x_{2 n}^{U}\right]} \\
A_{m} & {\left[x_{m 1}^{L}, x_{m 1}^{U}\right]} & {\left[x_{m 2}^{L}, x_{m 2}^{U}\right]} & \cdots & {\left[x_{m n}^{L}, x_{m n}^{U}\right]}
\end{array}
$$

Since finding the appropriate weight for each criterion is most of the times difficult, we apply an Imprecise Shannon's Entropy method in order to determine objective crisp weights [6].

\subsection{Interval Shannon's entropy method}

Since in a MADM problem each criterion may have different meanings and importance, it is not always easy to find the appropriate weight for each criterion. Therefore, various methods for finding weights were developed and most of them are categorized into two groups: subjective and objective weights.

Shannon's entropy method is one of them and is mainly used to obtain objective weights. The concept of Shannon's entropy has an important role in information theory and is used to refer to a general measure of uncertainty. In MADM, the greater the value of the entropy corresponding to a criterion is, which imply the smaller criterion's weight, the less the discriminate power of that criterion in the decision process is.

However, in the MADM problems under uncertainty, weights can also be described by intervals. In this case, an extension of the
Shannon's Entropy method [6] will be used, which implies the following steps:

Step 1. The normalized values $p_{i j}^{L}$ and $p_{i j}^{U}$ are calculated as:

$p_{i j}^{L}=\frac{x_{i j}^{L}}{\sum_{i=1}^{m} x_{i j}^{U}}, \quad p_{i j}^{U}=\frac{x_{i j}^{U}}{\sum_{i=1}^{m} x_{i j}^{U}}, \quad \mathrm{i}=1, . . m ; \quad \mathrm{j}=1, . . n$

where $m$ is the number of alternatives and $n$ the number of criterions.

Step 2. Lower bound $h_{i}^{L}$ and upper bound $h_{i}^{U}$ of interval entropy are obtained by:

$$
\begin{aligned}
& h_{j}^{L}=\min \left\{-h_{0} \sum_{i=1}^{m} p_{i j}^{L} \cdot \ln p_{i j}^{L},-h_{0} \sum_{i=1}^{m} p_{i j}^{U} \cdot \ln p_{i j}^{U}\right\}, j=1, . . n \\
& h_{j}^{U}=\max \left\{-h_{0} \sum_{i=1}^{m} p_{i j}^{L} \cdot \ln p_{i j}^{L},-h_{0} \sum_{i=1}^{m} p_{i j}^{U} \cdot \ln p_{i j}^{U}\right\}, j=1, . . n
\end{aligned}
$$

where $\mathrm{h}_{0}$ is equal to $(\ln \mathrm{m})^{-1}$ and $p_{i j}^{L} \cdot \ln p_{i j}^{L}$ or $p_{i j}^{U} \cdot \ln p_{i j}^{U}$ are 0 in case $p_{i j}^{L}=0$ or $p_{i j}^{U}=0$.

Step 3. Set the lower and the upper bound of the interval of diversification $d_{j}^{L}$ and $d_{j}^{U}$ as the degree of diversification as follows:

$d_{j}^{L}=1-h_{j}^{U}, d_{j}^{U}=1-h_{j}^{L}, \quad \mathrm{j}=1, . . n$

Step 4. Calculate the lower and upper bound of interval weight of each criterion $i$.

$$
w_{j}^{L}=\frac{d_{j}^{L}}{\sum_{s=1}^{n} d_{s}^{U}}, w_{j}^{U}=\frac{d_{j}^{U}}{\sum_{s=1}^{n} d_{s}^{L}}, j=1, . . n
$$

\subsection{TOPSIS method for interval data}

The basic concept of TOPSIS method is that the chosen alternative should have the shortest distance from the positive ideal solution and the farthest distance from the negative ideal solution.

The extended TOPSIS method for interval data [5] has the following steps:

Step 1. We first calculate the normalized decision matrix, using the formulas for each interval:

$$
n_{i j}^{L}=\frac{x_{i j}^{L}}{\sqrt{\sum_{i=1}^{m}\left[\left(x_{i j}^{L}\right)^{2}+\left(x_{i j}^{U}\right)^{2}\right]}}, i=1, . . m ; j=1, . . n
$$




$$
n_{i j}^{U}=\frac{x_{i j}^{U}}{\sqrt{\sum_{i=1}^{m}\left[\left(x_{i j}^{L}\right)^{2}+\left(x_{i j}^{U}\right)^{2}\right]}}, i=1, . . m ; j=1, . . n
$$

Step 2. We apply an Imprecise Shannon's Entropy method in order to determine the average objective crisp weights $\bar{w}_{j}$ for each criterion as: $\bar{w}_{j}=\left(w_{j}^{L}+w_{j}^{U}\right) / 2, \quad j=1, . . n$. We then normalize the weights as: $w_{j}=\frac{\bar{w}_{j}}{\sum_{j=1}^{n} \bar{w}_{j}}, j=1, . . n \quad$ so that $\sum_{j=1}^{n} w_{j}=1$. After that, we construct the weighted normalized interval decision matrix as:

$v_{i j}^{L}=w_{j} n_{i j}^{L}, i=1, . . m ; j=1, . . n$

$v_{i j}^{U}=w_{j} n_{i j}^{U}, i=1, . . m ; j=1, . . n$

Step 3. We identify the positive and the negative ideal solutions as:

$$
\begin{aligned}
& A^{+}=\left\{\left(\max _{i} v_{i j}^{U} \mid j \in B\right),\left(\min _{i} v_{i j}^{L} \mid j \in C\right)\right\} \\
& A^{-}=\left\{\left(\min _{i} v_{i j}^{L} \mid j \in B\right),\left(\max _{i} v_{i j}^{U} \mid j \in C\right)\right\}
\end{aligned}
$$

where $\mathrm{B}$ is associated with the benefit criteria and $\mathrm{C}$ with the cost criteria.

Step 4. The separation of each alternative from the positive and the negative ideal solutions are calculated as:

$$
\begin{aligned}
& d_{i}^{+}=\left\{\sum_{j \in B}\left(v_{i j}^{L}-v_{i j}^{+}\right)^{2}+\sum_{j \in C}\left(v_{i j}^{U}-v_{i j}^{+}\right)^{2}\right\}^{\frac{1}{2}}, i=1, . . m \\
& d_{i}^{-}=\left\{\sum_{j \in B}\left(v_{i j}^{U}-v_{i j}^{-}\right)^{2}+\sum_{j \in C}\left(v_{i j}^{L}-v_{i j}^{-}\right)^{2}\right\}^{\frac{1}{2}}, i=1, . . m
\end{aligned}
$$

Step 5. A closeness coefficient is defined to determine the ranking order of all alternatives in a descending order:

$$
\mathrm{CC}_{\mathrm{i}}=\frac{d_{i}^{-}}{d_{i}^{+}+d_{i}^{-}}, \quad i=1, . . m
$$

\subsection{ELECTRE III method for interval data}

In this section we propose an extension of the ELECTRE III method for interval data. The particularity of ELECTRE III method, comparative to the other versions of ELECTRE, consists mainly in the fact that it deals with pseudo-criteria instead of true criteria, allowing the following types of preferences between alternatives: strong preference, weak preference and indifference. In order to do that, it uses a preference threshold $p$, an indifference threshold $q$ and a veto threshold $v$.

Step 1. We first introduce a risk attitude factor for the decision maker, similar to [9], in order to transform an interval value into an exact value. However, we distinguish two different cases, depending on whether the criterion is a benefit or a cost criterion. That is why, in case of a benefit criterion, the exact value $\mathrm{x}_{\mathrm{ij}}$ is obtained as: $x_{i j}=\bar{x}_{i j}+\varepsilon \cdot \hat{x}_{i j}$, where $\bar{x}_{i j}$ is the middle value of the interval, and $\hat{x}_{i j}$ is the width of the interval, measured as: $\hat{x}_{i j}=x_{i j}^{U}-x_{i j}^{L}$, while in case of a cost criterion, the exact value $\mathrm{x}_{\mathrm{ij}}$ is obtained as: $x_{i j}=\bar{x}_{i j}-\varepsilon \cdot \hat{x}_{i j}$. The risk factor $\varepsilon$ represents the risk attitude of the decision maker and takes values between -0.5 and 0.5 . If the decision maker is risk adverse, then the range of the risk factor $\varepsilon$ will be $-0.5 \leq \varepsilon<0$, while if the decision maker is risk lover, the risk factor $\varepsilon$ will be $0<\varepsilon \leq 0.5$. The case in which the decision maker is risk neutral implies that $\varepsilon=0$.

Step 2. We calculate the concordance index $C_{j}\left(X_{i}, X_{l}\right)$ for each $\mathrm{X}_{\mathrm{i}}$ and $\mathrm{X}_{1}$ with respect to each criterion $\mathrm{j}$ as:

$C_{j}\left(X_{i}, X_{l}\right)=\left\{\begin{array}{cc}1, & X_{l j}-X_{i j} \leq q_{j} \\ \frac{X_{i j}-X_{l j}+p_{j}}{p_{j}-q_{j}}, & q_{j}<X_{l j}-X_{i j}<p_{j} \\ 0, & X_{l j}-X_{i j} \geq p_{j}\end{array}\right.$

Step 3. We calculate the discordance index $D_{j}\left(X_{i}, X_{l}\right)$ for each pair of alternatives with respect to each criterion:

$D_{j}\left(X_{i}, X_{l}\right)=\left\{\begin{array}{cc}1, & X_{l j}-X_{i j} \geq v_{j} \\ \frac{X_{l j}-X_{i j}-p_{j}}{v_{j}-p_{j}}, & p_{j}<X_{l j}-X_{i j}<v_{j} \\ 0, & X_{l j}-X_{i j} \leq p_{j}\end{array}\right.$

Step 4. We then calculate the overall concordance index for each $\mathrm{X}_{\mathrm{i}}$ and $\mathrm{X}_{1}$ : 


$$
C\left(X_{i}, X_{l}\right)=\sum_{j=1}^{n} w_{j} \cdot C_{j}\left(X_{i}, X_{l}\right)
$$

Step 5. The credibility matrix $S\left(X_{i}, X_{l}\right)$ of each pair of alternatives is calculated as:

$S\left(X_{i}, X_{l}\right)=\left\{\begin{array}{l}C\left(X_{i}, X_{l}\right), \quad D_{j}\left(X_{i}, X_{l}\right) \leq C\left(X_{i}, X_{l}\right), \forall j \\ C\left(X_{i}, X_{l}\right) \prod_{j \in S C\left(X_{i}, X_{l}\right)} \frac{1-D_{j}\left(X_{i}, X_{l}\right)}{1-C\left(X_{i}, X_{l}\right)}, \text { othewise }\end{array}\right.$

where $S C\left(X_{i}, X_{j}\right)$ is the set of criteria for which: $D_{j}\left(X_{i}, X_{l}\right)>C\left(X_{i}, X_{l}\right)$

Step 6. Then the concordance credibility and discordance credibility degrees are defined as:

$$
\begin{aligned}
& \phi^{+}\left(X_{i}\right)=\sum_{i \neq l} S\left(X_{i}, X_{l}\right), \quad i, l=1, . . m, \\
& \phi^{-}\left(X_{i}\right)=\sum_{i \neq l} S\left(X_{l}, X_{i}\right), \quad i, l=1, . . m
\end{aligned}
$$

where the concordance credibility degree represents that the degree of the alternative $X_{i}$ is at least as good as all the other alternatives, while the discordance credibility degree represents that the degree of all the other alternatives is at least as good as the alternative $\mathrm{X}_{\mathrm{i}}$.

Based on these two indicators, a net credibility degree for each alternative $X_{i}$ is defined as: $\phi\left(X_{i}\right)=\phi^{+}\left(X_{i}\right)-\phi^{-}\left(X_{i}\right)$, which has higher values when the alternative $X_{\mathrm{i}}$ is considered more attractive in comparison to the other alternatives.

Step 7. Finally, an outranking index $\mathrm{OTI}_{\mathrm{i}}$, is defined for each alternative in the following manner:

$$
\operatorname{OTI}\left(X_{i}\right)=\frac{\frac{\phi\left(X_{i}\right)}{m-1}+1}{2}
$$

Based on the outranking index we can then obtain the final ordering of the alternatives.

\subsection{Portfolio selection}

The portfolio selection method under uncertainty requires a combination of the results obtained from the two extended versions of TOPSIS and ELECTRE III methods for the case of interval data. It can actually be assumed that TOPSIS and ELECTRE III methods represent two decision makers of the portfolio selection.
That is why the best decision will be made when taking into consideration both experts opinions regarding the set of alternatives that may lead to best portfolio.

The portfolio selection algorithm for the case of interval data assumes taking the following steps:

Step 1. Apply the extended TOPSIS method for interval data and identify the closeness coefficient $\mathrm{CC}_{\mathrm{i}}$ for each alternative.

Step 2. Determine the threshold $\beta_{\text {TOPSIS }}=\frac{\sum_{i=1}^{m} C C_{i}}{m}$ and then identify the investment portfolio set of the TOPSIS method as: $\Omega_{T}=\left\{X_{i} \mid C C_{i} \geq \beta_{\text {TOPSIS }}\right\}$.

Step 3. Apply the extended ELECTRE III method for interval data and identify the outranking index $\mathrm{OTI}_{\mathrm{i}}$ for each alternative.

Step 4. Determine the threshold $\beta_{\text {ELECTRE }}=\frac{\sum_{i=1}^{m} O T I\left(X_{i}\right)}{m}$ and then identify the investment portfolio set of the ELECTRE III method as: $\Omega_{E}=\left\{X_{i} \mid \operatorname{OTI}\left(X_{i}\right) \geq \beta_{\text {ELECTRE }}\right\}$

Step 5. The decision upon the final investment portfolio set implies the intersection of the two portfolio sets that resulted based on the extended TOPSIS and ELECTRE III methods for interval data, $\Omega_{P}=\Omega_{T} \cap \Omega_{E}$.

According to the closeness coefficient, the investment portfolio ratios for the TOPSIS problem are calculated as:

$$
P_{T_{-} P\left(X_{i}\right)}= \begin{cases}\frac{C C\left(X_{i}\right)}{\sum_{X_{i} \in \Omega_{P}} C C\left(X_{i}\right)}, & X_{i} \in \Omega_{P} \\ 0, & \text { otherwise }\end{cases}
$$

While according to the outranking index, the investment portfolio ratios for the ELECTRE III problem are calculated as:

$$
P_{E_{-} P\left(X_{i}\right)}= \begin{cases}\frac{\operatorname{OTI}\left(X_{i}\right)}{\sum_{X_{i} \in \Omega_{P}} \operatorname{OTI}\left(X_{i}\right)}, & X_{i} \in \Omega_{P} \\ 0, & \text { otherwise }\end{cases}
$$

Step 6. Finally, we take into consideration the risk attitude of the decision maker, by 
assuming that the decision maker can either be risk adverse, risk neutral or risk lover. According to the risk attitude of the decision maker, we can determine the final portfolio ratios of the strict investment portfolio set based on the formulas:

$$
\begin{aligned}
P_{R A}= & \frac{\min \left(P_{T_{-} P}\left(X_{i}\right), P_{E_{-} P}\left(X_{i}\right)\right)}{\sum_{X_{i} \in \Omega_{P}} \min \left(P_{T_{-} P}\left(X_{i}\right), P_{E_{-} P}\left(X_{i}\right)\right)} \\
P_{R N}= & \frac{\left(P_{T_{-} P}\left(X_{i}\right)+P_{E_{-} P}\left(X_{i}\right)\right)}{2} \\
\sum_{X_{i} \in \Omega_{P}} \frac{\left(P_{T_{-} P}\left(X_{i}\right)+P_{E_{-} P}\left(X_{i}\right)\right)}{2} & \frac{\max \left(P_{T_{-} P}\left(X_{i}\right), P_{E_{-} P}\left(X_{i}\right)\right)}{\sum_{X_{i} \in \Omega_{P}} \max \left(P_{T_{-} P}\left(X_{i}\right), P_{E_{-} P}\left(X_{i}\right)\right)}
\end{aligned}
$$

where $\mathrm{P}_{\mathrm{RA}}$ represents the final portfolion ratios in case the decision maker is risk adverse, $P_{R N}$ for the risk neutral case, while $P_{R L}$ represents the final portfolion ratios in case the decision maker is risk lover.

\section{Numerical Example}

Although the portfolio decision has various fields in which it can be properly applied, mostly considering stock portfolio problems, in this paper we propose a distinct type of portfolio selection problem, by considering the case of a leasing company that has to decide in advance upon the most profitable combination of basic goods that will be financed in leasing.

Normally, there are two main types of goods that can be contracted in leasing: one representing standard goods, which are part of the basic annual offer of a leasing company and are acquired at the beginning of the year and secondly, the risky goods, which are not part of the basic annual offer, but can be acquired by the leasing company in case the client solicits it.

From the two types of goods, the company's offer containing standard goods can be modeled as a portfolio decision problem. That is why, the numerical example that was considered in this paper in order to highlight the procedure of the proposed algorithm, regards the decision making process of a leasing company to select the best portfolio structure of annual standard goods that will be financed in leasing. Since the decision is based on profitability and other financial criteria, we were able to model the annual standard goods portfolio selection process as a multi-attribute decision making problem.

The main standard goods which have the potential to be included in the annual offer of a leasing company are considered to be the following: personal vehicles, utility vehicles, heavy commercial vehicles, transport buses, industrial equipment, construction equipment and office and medical technology equipment.

Based on the lease transaction history of a leasing company, as well as from the general characteristics of a lease contract in case of each particular standard good, the next basic elements were selected, having the following descriptions:

In case of personal vehicles, the average price is $20.000 €$, with a $15 \%$ to $20 \%$ payment in advance, an average contract period of 3 to 4 years, a $9.5 \%$ interest rate and a $20 \%$ residual value.

In case of utility vehicles, the average price is $48.000 €$, with a $15 \%$ to $20 \%$ payment in advance, an average contract period of 4 to 5 years, a $9.75 \%$ interest rate and a $20 \%$ residual value.

In case of heavy commercial vehicles, the average price is $90.000 €$, with a $25 \%$ to $30 \%$ payment in advance, an average contract period of 4 to 5 years, a $9.75 \%$ interest rate and a $20 \%$ residual value.

In case of transport buses, the average price is $43.000 €$, with a $25 \%$ to $30 \%$ payment in advance, an average contract period of 3 to 4 years, a 9.75\% interest rate and a $20 \%$ residual value.

In case of industrial equipment, the average price is $70.000 €$, with a $20 \%$ to $25 \%$ payment in advance, an average contract period of 4 to 5 years, a $10 \%$ interest rate and a $20 \%$ residual value.

In case of construction equipment, the average price is $47.000 €$, with a $20 \%$ to 25 payment in advance, an average contract period of 3 to 4 years, a $10 \%$ interest rate and a $20 \%$ residual value. 
In case of office and medical technology equipment, the average price is $25.000 €$, with a $15 \%$ to $20 \%$ payment in advance, an average contract period of 4 to 5 years, a $10 \%$ interest rate and a $20 \%$ residual value.

According to each minimum and maximum value of the main elements considered in the lease contracts, meaning the percent of advance payment, as well as the contract duration, we were able to build up the intervals of the main financial variables, as well as the profitability ratios for each of the 7 standard goods studied in the portfolio decision problem. That is how, different intervals for each of the 7 alternatives, describing the investment costs and earnings, the net present values of each lease transaction, as well as the rentability ratios and the investment payback time were determined.

The following 6 criteria were selected to be most relevant in the goods portfolio selection problem of a leasing company:
$\mathrm{C} 1=$ First year Earnings (FYE)

$\mathrm{C} 2=$ Investment Cost $(\mathrm{C})$

C3= Investment Net Present Value (NPV)

$\mathrm{C} 4=$ Investment Rentability (R)

$\mathrm{C} 5=$ Investment payback time $(\mathrm{PT})$

C6 $=$ Market demand of the goods (MD)

The last criterion refers to the estimated level of market demand for the year 2010 of each standard good, and was obtained by allowing a $\pm 2 \%$ variation of the market demand of the previous year.

In order to determine the objective importance of each criterion, we applied the Imprecise Shannon's Entropy method for interval data. The following average importance coefficient vector resulted: (25\%, $17.5 \%, 80 \%, 50 \%, 20.5 \%$ and $73.8 \%$ ).

After normalization, the importance coefficient vector became: $(9.4 \%, 6.6 \%$, $30 \%, 18.8 \%, 7.7 \%$ and $27.7 \%$ )

Table1. The interval decision matrix

\begin{tabular}{|c|c|c|c|c|c|c|}
\hline & Max & Min & Max & Max & Min & Max \\
\hline & $\begin{array}{c}\text { C1 } \\
\text { (FYE) }\end{array}$ & $\begin{array}{l}\text { C2 } \\
\text { (C) }\end{array}$ & $\begin{array}{c}\text { C3 } \\
\text { (NPV) }\end{array}$ & $\begin{array}{l}\text { C4 } \\
(\mathrm{R})\end{array}$ & $\begin{array}{c}\text { C5 } \\
(\text { PT })\end{array}$ & $\begin{array}{c}\text { C6 } \\
\text { (MD) }\end{array}$ \\
\hline A1. Personal vehicles & $\begin{array}{l}{[4258.9} \\
5627.8]\end{array}$ & $\begin{array}{c}{[16000,} \\
17935]\end{array}$ & $\begin{array}{l}{[399.7} \\
1457.4]\end{array}$ & {$[8.6,19]$} & {$[3.2,4.3]$} & {$[35.9,39.9]$} \\
\hline A2. Utility vehicles & $\begin{array}{l}{[8747.2} \\
10847.1]\end{array}$ & $\begin{array}{l}{[38400,} \\
43044]\end{array}$ & $\begin{array}{l}{[1399.4} \\
14022.2]\end{array}$ & {$[13.1,23.9]$} & {$[4,5.1]$} & {$[7.9,11.9]$} \\
\hline $\begin{array}{l}\text { A3. Heavy commercial } \\
\text { vehicles }\end{array}$ & $\begin{array}{l}{[14575.9} \\
18157.3]\end{array}$ & $\begin{array}{l}{[63000} \\
71212.5]\end{array}$ & $\begin{array}{l}{[2520.9} \\
6866.2]\end{array}$ & {$[13.4,24.3]$} & {$[4,5.1]$} & {$[9.3,13.3]$} \\
\hline A4. Transport buses & $\begin{array}{l}{[8154.1} \\
10813.6]\end{array}$ & $\begin{array}{l}{[30100,} \\
34023.8]\end{array}$ & $\begin{array}{l}{[955.6} \\
3002.8]\end{array}$ & {$[9.2,19.8]$} & {$[3.2,4.2]$} & {$[0.3,4.3]$} \\
\hline A5. Industrial Equipment & $\begin{array}{c}{[12108.5} \\
15034.9]\end{array}$ & $\begin{array}{l}{[52500} \\
59080]\end{array}$ & $\begin{array}{c}{[2224.2} \\
5900.5]\end{array}$ & {$[13.6,24.7]$} & {$[4,5]$} & {$[4.2,8.2]$} \\
\hline $\begin{array}{l}\text { A6. Construction } \\
\text { Equipment }\end{array}$ & $\begin{array}{l}{[9522.7} \\
12587.2]\end{array}$ & $\begin{array}{l}{[35250,} \\
39668]\end{array}$ & $\begin{array}{l}{[1164.9} \\
3598.3]\end{array}$ & {$[9.4,20.1]$} & {$[3.1,4.2]$} & {$[2.4,6.4]$} \\
\hline $\begin{array}{l}\text { A7. Office and medical } \\
\text { technology equipment }\end{array}$ & {$[4579.4,5674]$} & $\begin{array}{l}{[20000,} \\
22418]\end{array}$ & $\begin{array}{c}{[814,} \\
2207.8]\end{array}$ & $\begin{array}{c}{[13.5,} \\
24.5]\end{array}$ & {$[4,5.1]$} & {$[0.6,4.6]$} \\
\hline
\end{tabular}


Based on the calculated importance coefficients associated to each criterion, we were able to determine the following order of importance of the criterions: $\mathrm{C} 3, \mathrm{C} 6, \mathrm{C} 4, \mathrm{C} 1$, $\mathrm{C} 5$ and finally $\mathrm{C} 2$.

The interval decision matrix, for the goods portfolio selection problem, is presented in Table 1.

The proposed portfolio algorithm for interval data was then applied. First, the TOPSIS method for interval data was used in order to determine the portfolio set of standard goods that are the closest to the ideal positive solution and the farthest to the ideal negative solution. It resulted the following complete order of the standard goods: A1, A3, A5, A2, A6, A4 and A7, out of which only the alternatives A1, A3 and $\mathrm{A} 5$ were selected to be the best by having higher closeness coefficient than the average value $\beta_{\text {TOPSIS }}$ of 0,3662 .

Then, the extended version of ELECTRE III method for interval data was applied, in order to identify the second portfolio set of standard goods, based on pair comparisons of each combination of goods. For that, we first had to decide upon the level of the parameter $\varepsilon$. We used -0.5 in case the decision maker is risk adverse, 0 for the risk neutral case and 0.5 in case the decision maker is risk lover.

Secondly, the threshold levels of the parameters $\mathrm{p}, \mathrm{q}$ and $\mathrm{v}$ were predetermined. Similar to Chen and Hung's approach [4] in which $\mathrm{q}=1 / 6 ; \mathrm{p}=2 / 6$ and $\mathrm{v}=3 / 6$, we used the following formulas for computing the thresholds. Let $\mathrm{MDj}$ be the maximum difference between two alternatives for criterion $\mathrm{j}$. We set the indifference threshold qj to $1 / 6 * \mathrm{MDj}$, the preference threshold pj to be $2 / 6 * \mathrm{MDj}$ and the veto threshold vj to $3 / 6 * \mathrm{MDj}$.. After that we computed the concordance and discordance index in order to determine the credibility matrix and the concordance and discordance credibility degrees. Based on that, we were able to calculate the OTI values for each alternative and to establish the final ranking of the alternatives for each possible decision maker's risk attitude, as presented in Table 2, where between brackets are the OTI values.
Table2. The results of ELECTRE III method

\begin{tabular}{|c|c|c|c|}
\hline Rank & $\begin{array}{c}\text { Risk } \\
\text { adverse }\end{array}$ & $\begin{array}{c}\text { Risk } \\
\text { neutral }\end{array}$ & $\begin{array}{c}\text { Risk } \\
\text { lover }\end{array}$ \\
\hline $\mathbf{1}$ & $\mathbf{A 1}(0,56)$ & $\mathbf{A 1}(0,56)$ & $\mathbf{A 1}(0,56)$ \\
\hline $\mathbf{2}$ & $\mathbf{A 5}(0,53)$ & $\mathbf{A 5}(0,53)$ & $\mathbf{A 5}(0,53)$ \\
\hline $\mathbf{3}$ & $\mathbf{A 3}(0,501)$ & $\mathbf{A 2}(0,502)$ & $\mathbf{A 2}(0,504)$ \\
\hline $\mathbf{4}$ & $\mathbf{A 6}(0,5)$ & $\mathbf{A 3}(0,502)$ & $\mathbf{A 3}(0,504)$ \\
\hline $\mathbf{5}$ & $\mathbf{A 2}(0,496)$ & $\mathbf{A 6}(0,5)$ & $\mathbf{A 6}(0,5)$ \\
\hline $\mathbf{6}$ & $\mathbf{A 7}(0,48)$ & $\mathbf{A 7}(0,47)$ & $\mathbf{A 7}(0,47)$ \\
\hline $\mathbf{7}$ & $\mathbf{A 4}(0,44)$ & $\mathbf{A 4}(0,44)$ & $\mathbf{A 4}(0,44)$ \\
\hline & beta=0,5 & beta=0,5 & beta=0,5 \\
\hline
\end{tabular}

Although we notice the presence of a few differences in the final ranking of the alternatives based on the decision maker risk attitude, when intersecting the portfolio sets of the 2 MADM methods, only the following 3 alternatives are selected in the final annual goods portfolio of the leasing company: A1, $\mathrm{A} 3$ and $\mathrm{A} 5$, representing personal vehicles, heavy industrial vehicles and industrial equipment. When considering the 3 types of decision maker's risk attitude, we computed the following portfolio structures, described in Figure 1.

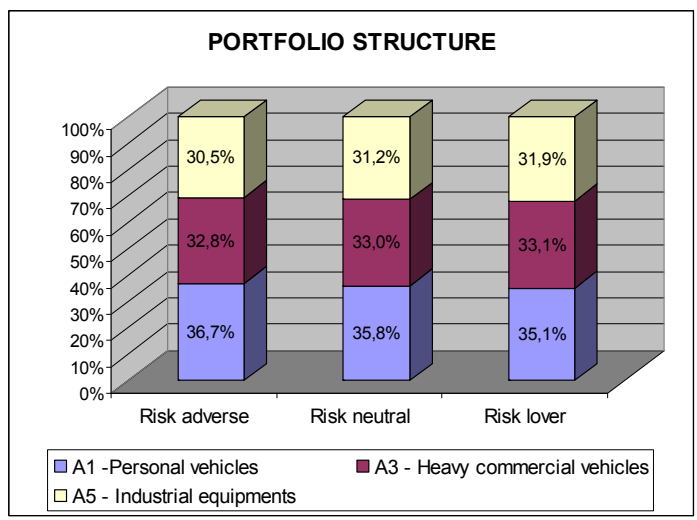

Figure 1. The annual goods portfolio structure

One can notice that in case of risk adverse decision maker, the best combination of standard goods consists in $36.73 \%$ personal vehicles, $32,81 \%$ heavy commercial vehicles and $30,46 \%$ industrial equipments. In case of risk neutral and risk lover decision maker, the structure is similar, but the company should 
invest $1-2 \%$ less in personal vehicles and almost $1-2 \%$ more in industrial equipment.

\section{Simulations}

Our further step in the analysis consists in performing some numerical simulations [12], in order to check how the annual goods portfolio structure obtained from applying the proposed algorithm described earlier, changes in case each attribute of the initial interval matrix is randomly generated and considered to follow a uniform distribution between intervals. The numerical simulations were conducted based on several approaches.

At level of an itteration, we computed the portfolio structure. For that, we applied the proposed portfolio algorithm and identified the percent of each annual good in the portfolio. After 2000 iterations, we determined the average portfolio structure, by calculating the average weights of the standard goods in the final portfolio (i.e. the weight of a good in the final portfolio is the average of its weights from each itteration's portfolio). The results of the first simulation are presented in Table 3 .

Table 3. The portfolio structure when the portfolio was computed at every iteration

\begin{tabular}{|c|c|c|c|}
\hline $\begin{array}{c}\text { Portfolio } \\
\text { structure }\end{array}$ & $\begin{array}{c}\text { Risk } \\
\text { adverse }\end{array}$ & $\begin{array}{c}\text { Risk } \\
\text { neutral }\end{array}$ & $\begin{array}{c}\text { Risk } \\
\text { lover }\end{array}$ \\
\hline A1 & $44,2 \%$ & $44,2 \%$ & $44,2 \%$ \\
\hline A2 & $6,9 \%$ & $7,0 \%$ & $7,1 \%$ \\
\hline A3 & $29,1 \%$ & $28,7 \%$ & $28,3 \%$ \\
\hline A5 & $19,5 \%$ & $19,8 \%$ & $20,0 \%$ \\
\hline A6 & $0,3 \%$ & $0,4 \%$ & $0,4 \%$ \\
\hline
\end{tabular}

The second approach consisted in solving only the TOPSIS and ELECTRE III methods for crisp values, at every itteration, in order to determine the closeness coefficient $\mathrm{CC}_{\mathrm{i}}$ and the outranking index $\mathrm{OTI}_{\mathrm{i}}$ for each alternative. After 2000 iterations, the average values of $\mathrm{CC}_{\mathrm{i}}$ and $\mathrm{OTI}_{\mathrm{i}}$ for each alternative were calculated and then, based on the average thresholds $\beta_{\text {TOPSIS }}$ and $\beta_{\text {ELECTRE }}$ (i.e. thresholds computed using the average values of $\mathrm{CC}_{\mathrm{i}}$ and $\mathrm{OTI}_{\mathrm{i}}$ ), the intersection portfolio set of annual goods was finally determined. Using the formulas presented at Step 5 of the portfolio selection algorithm, the final 3 portfolios for the cases of risk adverse, risk lover and risk neutral decision maker were obtained. The results of the simulation are presented in Table 4.

Table 4. The portfolio structure when the portfolio was computed at the end of 2000 iterations

\begin{tabular}{|c|c|c|c|}
\hline $\begin{array}{c}\text { Portfolio } \\
\text { structure }\end{array}$ & $\begin{array}{c}\text { Risk } \\
\text { adverse }\end{array}$ & $\begin{array}{c}\text { Risk } \\
\text { neutral }\end{array}$ & $\begin{array}{c}\text { Risk } \\
\text { lover }\end{array}$ \\
\hline A1 & $38,7 \%$ & $38,9 \%$ & $39,1 \%$ \\
\hline A3 & $33,8 \%$ & $32,2 \%$ & $30,9 \%$ \\
\hline A5 & $\mathbf{2 7 , 6 \%}$ & $\mathbf{2 8 , 9 \%}$ & $\mathbf{3 0 , 1 \%}$ \\
\hline
\end{tabular}

The major differences from the initial portfolio solution obtained when applying the proposed algorithm were noticed in the case of the first approach of the simulation. From table 3 we see that the simulated portfolio contains two more standard goods, representing transport vehicles and construction equipment, which were not part of the final solution in the numerical example. However, their contribution to the final simulated portfolio is quite small.

On the other hand, the second approach of simulation in which the final portfolio was computed at the end of the 2000 iterations, generated a portfolio structure almost similar to the initial portfolio solution.

Lastly, we computed a final simulation, based on a different random generation of the attributes between intervals. This time, we randomly generated only a $\varepsilon$ value in the interval $[-0.5 ; 0.5]$ at each iteration and calculated each attribute value by applying the formula presented earlier, $x_{i j}=\bar{x}_{i j}+\varepsilon \cdot \hat{x}_{i j}$, where $\bar{x}_{i j}$ is the middle value of the interval, and $\hat{x}_{i j}$ is the width of the interval, measured as: $\hat{x}_{i j}=x_{i j}^{U}-x_{i j}^{L}$, for the case of a benefit criterion and $x_{i j}=\bar{x}_{i j}-\varepsilon \cdot \hat{x}_{i j}$, for the case of a cost criterion. In this manner we were able to check how much the pre-specified $\varepsilon$ value representing the risk factor of a decision maker affects the final portfolio structure. 
We considered the same two approaches for computing the final portfolio as in the case of the previous simulation, meaning the case when the portfolio is computed at the end of the 2000 iterations and the case when the portfolio is computed at each itteration. However, in this case, the final portfolio is the same, no matter if the portfolio was computed at every itteration or if it was computed only at the end of the 2000 iterations. Thus, we present only one set of results: the final portfolio structure is shown in Table 5.

Table 5. The portfolio structure when the simulation was based on the risk factor

\begin{tabular}{|c|c|c|c|}
\hline $\begin{array}{c}\text { Portfolio } \\
\text { structure }\end{array}$ & $\begin{array}{c}\text { Risk } \\
\text { adverse }\end{array}$ & $\begin{array}{c}\text { Risk } \\
\text { neutral }\end{array}$ & $\begin{array}{c}\text { Risk } \\
\text { lover }\end{array}$ \\
\hline A1 & $38,3 \%$ & $38,5 \%$ & $38,8 \%$ \\
\hline A3 & $33,9 \%$ & $32,1 \%$ & $30,6 \%$ \\
\hline A5 & $27,8 \%$ & $29,3 \%$ & $30,6 \%$ \\
\hline
\end{tabular}

The results of this last simulation indicated high similarities between the simulated portfolio structure and the initial solution.

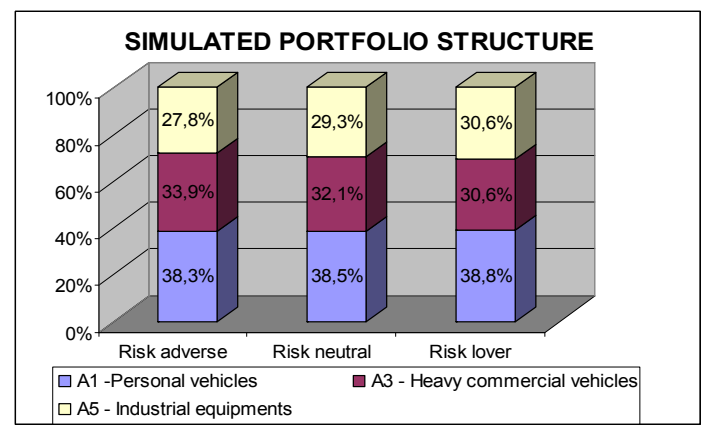

Figure2. The portfolio structure when the simulation was based on the risk factor

This also confirms the fact that the proposed extension of the ELECTRE III method for interval data presented in this article is not strongly affected by the value of the $\varepsilon$ risk factor.

\section{Conclusions}

In this paper we presented an extension of the ELECTRE III method for interval data and then formulated an extension of a portfolio selection algorithm for multi-attribute decision problems, in which there is uncertainty in data.
An example of product portfolio selection for a leasing company was then analyzed in order to highlight the procedure of the proposed algorithm, followed by some numerical simulations that deeper checked the way the algorithm actually works.

\section{REFERENCES}

1. AMIRI, M., N. E. NOSRATIAN, A. JAMSHIDI, A. KAZEMI, Developing a New ELECTRE Method with Interval Data in Multiple Attribute Decision Making Problems, Journals of Applied Sciences, 8(22), 2008, pp. 4017-4028.

2. ANDREICA, M. E., M. I. ANDREICA, N. CĂTĂNICIU, Multidimensional Data Structures and Techniques for Efficient Decision Making, Proc. of the 10th WSEAS International Conference MCBE'09, 2009, pp. 249-254.

3. ANDREICA M. E., I. DOBRE, M. ANDREICA, B. NITUU, R. ANDREICA, A New Approach of the Risk Project from Managerial Perspective, Ec. Computation and Ec. Cybernetics Studies and Research Journal, vol. 42, no. 1-2 / 2008, pp. 121-130.

4. CHEN, C. T., W. Z.HUNG, A New Decision-Making Method for Stock Portfolio Selection Based on Computing with Linguistic Assessment, Journal of Applied Mathematics and Decision Sciences Volume, 2009.

5. JAHANSHAHLOO, G. R., F. H. LOTFI, M. IZADIKHAH, An Algorithmic Method to Extend TOPSIS for Decision-making Problems with Interval Data, Applied Mathematics and Computation 175 - 2006, pp. 1375-1384.

6. LOTFI, F. H., R. FALLAHNEJAD, Imprecise Shannon's Entropy and Multi Attribute Decision Making, Entropy, 2010, 12, pp. 53-62.

7. RESTEANU, C., M. SOMODI, M. ANDREICA, E. MITAN, Distributed and Parallel Computing in MADM Domain using the OPTCHOICE Software, Proc. of the $7^{\text {th }}$ WSEAS Intl. Conf. on Applied Computer Science, 2007, pp. 376-384. 
8. STOICA, M., D. NICOLAE, M. A. UNGUREANU, A. ANDREICA, M. E. ANDREICA, Fuzzy Sets and Their Applications, Proc. WSEAS Intl. Conf. on Math. and Comp. in Business. and Econ., 2008, pp. 197-202.

9. YE, F., Y. N. LI, Group Multi-attribute Decision Model to Partner Selection in the Formation of Virtual Enterprise under Incomplete Information, Expert Systems with Applications, 36, 2009, pp. 9350-9357.

10. RESTEANU, C., F. G. FILIP, et al., On Optimal Choice Problem Solving, Proc. of IEEE International Conference on Systems, Man and Cybernetics Information, Intelligence and Systems, vols 1-4, Oct 14-17, Beijing, China, 1996, pp. 1864-1869.
11. RĂDULESCU M., C.-Z. RĂDULESCU, G. ZBĂGANU, Asset Allocation Models in Discrete Variable, Studies in Informatics and Control, vol 18 - 1, 2009, pp. 63-70.

12. RESTEANU, C., F G. FILIP, C. IONESCU, et al., Knowledge-based Simulation in Multiattribute Decision Making, Proc. of. EUROSIM Conference, Vienna Austria, Sep 11-15, 1995, pp. 1271-1276 